\title{
Alteração de atributos químicos no solo de rampas utilizadas no tratamento de águas residuárias
}

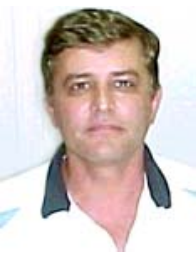

\author{
Antonio T. de Matos ${ }^{1}$, Andressa B. Pinto ${ }^{2}$, Odilon G. Pereira ${ }^{3}$ \& Flávia M. Barros ${ }^{4}$ \\ ${ }^{1}$ DEA/UFV, CEP 36.570-000, Viçosa, MG, Fone (031) 3899-1886,E-mail: atmatos@ufv.br \\ ${ }^{2}$ Eng. Agrícola, M.S. em Eng. Agrícola, atmatos@ufv.br \\ ${ }^{3}$ DZO/UFV, CEP 36.570-000, Viçosa, MG, Fone (031) 3899-3323, E-mail: odilon@ufv.br. \\ ${ }^{4}$ Mestranda em Eng. Agrícola. DEA/UFV. CEP 36571-000, Viçosa-MG. E-mail:mariamariani@yahoo.com.br
}

Protocolo $179-14 / 11 / 2003$ - Aprovado em 15/2/2005

\begin{abstract}
Resumo: 0 tratamento de águas residuárias ricas em material orgânico por meio da disposição direta sobre o solo é uma alternativa viável, tendo em vista o baixo custo de implantação e a possibilidade de aproveitamento dos nutrientes contidos nessas águas. Neste trabalho, foram avaliados os efeitos da aplicação de água residuária da lavagem e despolpa dos frutos do cafeeiro (ARC), em alguns atributos químicos de um solo cultivado com três espécies forrageiras (azevém, aveia preta e milheto). A ARC foi aplicada em parcelas de $6 \mathrm{~m}^{2}$ e com declividade de $5 \%$, com aplicação de taxa média de $250 \mathrm{~kg} \mathrm{ha}^{-1} \mathrm{dia}^{-1} \mathrm{de}^{\mathrm{DBO}} \mathrm{S}_{5}$ da ARC. Os nutrientes aplicados no solo por meio da ARC, à exceção do potássio, não foram suficientes para proporcionar acúmulo na camada superficial do solo que, ao contrário, apresentou redução nas concentrações de $\mathrm{P}$ disponível, $\mathrm{Ca}$ e Mg trocáveis. Nas parcelas que receberam ARC, as maiores concentrações de nitrato foram observadas na camada superficial do solo, de 0 a $0,10 \mathrm{~m}$, independentemente da espécie vegetal cultivada. Menores concentrações em subsuperfície $(0,30-0,50 \mathrm{~m})$ foram encontradas nas parcelas cultivadas com milheto e azevém, quando fertirrigados com ARC.
\end{abstract}

Palavras-chave: disposição no solo, despolpa dos frutos do cafeeiro, tratamento por escoamento superficial, gramíneas forrageiras

\section{Alteration of the chemical attributes in ramps of soil used in the treatment of wastewater}

\begin{abstract}
The treatment of wastewater, rich in organic material through the direct disposal on soil is a viable alternative due to small implantation costs and the possibility of use of nutrients contained in those waters. In this work, the effect of the application of wastewater from washing and pulping coffee fruits $(A R C)$ on the chemical attributes of a soil cultivated with three forage species (ryegrass, oat and millet) was appraised. ARC was applied in plots of $6 \mathrm{~m}^{2}$ and with slope of $5 \%$. A mean rate equivalent to $250 \mathrm{~kg} \mathrm{ha}^{-1} \mathrm{dia}^{-1}$ of $\mathrm{DBO}_{5}$ of the $\mathrm{ARC}$ was applied. The applied nutrients in the soil through $A R C$, except the potassium, were not enough to provide accumulation in the soil surface layer, which on the contrary, presented reduction in the concentrations of available $\mathrm{P}$, exchangeable $\mathrm{Ca}$ and $\mathrm{Mg}$. In the plots that received $\mathrm{ARC}$, the largest concentrations of nitrate were observed in the soil surface layer $(0$ to $0.10 \mathrm{~m})$, independently of the cultivated vegetable species. Smaller concentrations in subsurface layer $(0.30-0.50 \mathrm{~m})$ were found in the portions cultivated with millet and ryegrass when fertirrigated with ARC.
\end{abstract}

Key words: wastewater disposal, pulping of coffee, overland flow treatment, forage grasses

\section{INTRODUÇÃO}

No Brasil, a cultura do cafeeiro é, sem dúvida, de notória importância e expressividade para a economia do País, porém o mercado mundial se encontra bastante exigente em termos de qualidade da bebida que os grãos de café podem proporcionar. A fim de se obter melhorias na qualidade de bebida, o fruto e, posteriormente, os grãos, devem ser adequadamente processados. A qualidade do grão, que determina seu preço de mercado e a aceitação do produto no comércio internacional, está relacionada às características como cor, aspecto, número de defeitos, aroma e gosto da bebida que, por sua vez, dependem 
de fatores tais como: composição química do grão, processamento pós-colheita, secagem e armazenagem, além da torração e preparo da bebida (Silva \& Berbert, 1999; Carvalho et al., 1997).

O fruto do cafeeiro pode ser processado de duas formas: por via seca, isto é, secando integralmente os frutos, ou por via úmida, que consiste na secagem dos frutos sem casca (polpa) ou sem casca e sem mucilagem, dando origem aos grãos descascados (despolpados) e desmucilados, respectivamente.

O processamento dos frutos do cafeeiro por via úmida proporciona, de forma geral, a produção de grãos de bebida suave, com boas cotações no mercado, mas é responsável pela geração de grandes volumes de águas residuárias, ricas em materiais orgânicos altamente poluentes.

O impacto ambiental proporcionado pelas águas residuárias da lavagem, descascamento e desmucilagem de frutos do cafeeiro (ARC) é grande, não somente pela carga orgânica contaminante que alcança os corpos d'água mas, também, pelo enorme volume de águas limpas utilizado no processamento do fruto e que é devolvido ao meio ambiente com baixa qualidade (Campos, 1993).

Diversos são os métodos disponíveis para o tratamento de águas residuárias ricas em material orgânico, porém toda e qualquer tecnologia gerada para a disposição de resíduos orgânicos no solo, por mais modernas e complexas que sejam, se não contemplarem os riscos potenciais de contaminação ambiental estarão, inexoravelmente, condenadas ao fracasso (Matos \& Sediyama, 1996). A disposição de águas residuárias no solo pode proporcionar aumento da produtividade, melhorar a qualidade dos produtos colhidos e reduzir a poluição ambiental (Matos et al., 1995), além do que pode, também, promover melhorias em algumas propriedades físicas dos solos. Dentre os métodos disponíveis para o tratamento de águas residuárias destaca-se o método por escoamento superficial, no qual a água residuária é aplicada em altas taxas na parte superior de uma rampa vegetada, ficando sujeita ao escoamento superficial, condição que possibilita sua depuração ao longo da rampa de tratamento. Neste tratamento, o crescimento da vegetação permitirá proteção ao solo contra a erosão e providenciará uma camada suporte, na qual os microrganismos se estabelecerão. Devido aos nutrientes produzidos e à grande disponibilidade de água, essa vegetação crescerá muito rapidamente, produzindo grande quantidade de massa verde, exigindo, com isso, grande freqüência de cortes (Coraucci Filho et al., 1999).

A ação do solo como depurador de águas residuárias é decorrente da interceptação dos sólidos em suspensão, remoção de nutrientes por adsorção à matriz do solo ou adsorção pelas plantas, além da oxidação do material orgânico, promovido principalmente por bactérias que se estabelecem no colo das plantas e no próprio solo; entretanto, para que a disposição de efluentes líquidos no solo não traga riscos de salinização, torna-se necessário o conhecimento da capacidade de suporte de cada sistema solo-planta para que se possa estabelecer a taxa de aplicação mais adequada, de forma a resguardar a integridade dos recursos naturais (Matos \& Sediyama, 1996).
Em sistemas de tratamento por escoamento superficial, rampas vegetadas de solo são submetidas a intensiva aplicação de águas residuárias, geralmente ricas em nitrogênio. Com a mineralização do nitrogênio orgânico e a nitrificação das formas minerais, pode ocorrer grande disponibilização de nitrato no solo e, dada às condições favoráveis à lixiviação deste ânion no perfil do solo, torna-se grande o risco de contaminação de águas subterrâneas (Matos et al., 2001). Considerando-se que ânions $\mathrm{NO}_{3}^{-}$são fracamente adsorvidos em solos eletronegativos, eles tendem a ser carreados com águas de escoamento superficial ou lixiviados no perfil do solo. Desta forma, considerável proporção de nitrogênio aplicado no solo pode alcançar águas superficiais e subterrâneas. Em razão de sua alta solubilidade em água, o nitrato deve acompanhar a água de recarga dos aqüíferos subterrâneos, trazendo sérios riscos sanitários para a população que se utiliza dessas águas para dessedentação (Muchovej \& Rechcigl, 1994; Owens, 1994).

Os riscos de contaminação de águas subterrâneas com nitrato são maiores em regiões onde há altos índices pluviométricos ou ocorre a aplicação de excessivas lâminas de águas residuárias e o solo apresente alta permeabilidade. Oliveira (1993) detectou valores de concentração de nitrato 10 vezes superiores ao normal nas águas subterrâneas de uma área fertirrigada, durante vários anos, com águas residuárias $\left(160 \mathrm{~m}^{3} \mathrm{ha}^{-1}\right)$ provenientes da atividade suinícola. Em países de clima temperado, taxas de aplicação de nitrogênio inferiores a 400-430 $\mathrm{kg} \mathrm{ha}^{-1}$ de $\mathrm{N}$ têm sido recomendadas como seguras, do ponto de vista de contaminação de águas subterrâneas (King et al., 1985; Sutton et al., 1982, citados por Westerman et al., 1987) porém, segundo Burns et al. (1985), esses valores estão demasiadamente altos para solos arenosos.

Em vista dos riscos que a disposição não-criteriosa da ARC pode proporcionar ao solo e às águas subterrâneas, neste trabalho se objetivou avaliar as alterações em alguns atributos químicos no solo de rampas vegetadas utilizadas no tratamento por escoamento superficial de águas residuárias do beneficiamento dos frutos do cafeeiro.

\section{MATERIAL E MÉTODOS}

O experimento foi implantado e conduzido em uma área de aproximadamente $350 \mathrm{~m}^{2}$, pertencente à Fazenda Laje, localizada no Município de Viçosa, MG, situado na Zona da Mata mineira, a $689,73 \mathrm{~m}$ de altitude, em longitude de $42^{\circ} 52^{\prime} 40^{\prime \prime} \mathrm{W}(\mathrm{G})$ e latitude de $20^{\circ} 45^{\prime} 20^{\prime \prime} \mathrm{S}$.

Para implantação do experimento, o terreno da área experimental foi sistematizado a fim de garantir declividade de $5 \%$ em toda a área. No arranjo experimental, foi utilizado o delineamento em blocos casualizados, com quatro repetições, sendo os tratamentos definidos por três espécies forrageiras: pelo azevém (Lolium multiflorum L.), pela aveia-preta (Avena strigosa Schreb) e pelo milheto (Pennisetum americanum L.). A semeadura foi efetuada em parcelas de 3,0 x 2,0 m, com espaçamento de $0,20 \mathrm{~m}$ entre linhas de plantio e $1 \mathrm{~m}$ entre parcelas. As densidades de plantio utilizadas foram de 80 $\mathrm{kg} \mathrm{ha}^{-1}$ para aveia preta comum, $30 \mathrm{~kg} \mathrm{ha}^{-1}$ para o azevém comum e $15 \mathrm{~kg} \mathrm{ha}^{-1}$ para o milheto. 
As águas residuárias do beneficiamento dos frutos do cafeeiro (ARC), coletadas em lagoa de tratamento, próximo ao ponto de lançamento da água residuária bruta (tempo de detenção menor que dois dias), foram acondicionadas separadamente em tanques de $500 \mathrm{~L}$, de onde eram aplicadas nas parcelas experimentais, com o auxílio de regadores. Nas primeiras três semanas, foi aplicada ARC numa taxa equivalente a $750 \mathrm{~kg} \mathrm{ha}^{-1} \mathrm{dia}^{-1}$ de $\mathrm{DBO}_{5}$, para avaliação do comportamento das plantas ante a carga orgânica e de sais aplicados com a ARC. Como se verificou que o azevém e, principalmente, a aveia-preta, começaram a apresentar sinais de toxicidade, fezse opção por reduzir a carga orgânica aplicada. As taxas de aplicação passaram a ser equivalentes a $250 \mathrm{~kg} \mathrm{ha}^{-1} \mathrm{dia}^{-1} \mathrm{de}$ $\mathrm{DBO}_{5}$, o que foi realizado nas 14 semanas, posteriores nos dias úteis da semana.

Quinzenalmente, foram coletadas amostras da ARC, que eram conduzidas e analisadas no Laboratório de Qualidade da Água do Departamento de Engenharia Agrícola. A quantificação da $\mathrm{DBO}_{5}$, realizada a partir da concentração do oxigênio dissolvido (obtido pelo método iodométrico) e da DQO, realizada segundo o método do refluxo aberto, foi executadas de acordo com a metodologia apresentada pela APHA (1995). Para análise de fósforo (ortofosfato), nitrato e amônio, foi utilizado o método colorimétrico (EMBRAPA, 1997). O potássio foi quantificado por fotometria de chama, enquanto o cálcio, o magnésio e a dureza total o foram por titulometria (APHA, 1995; EMBRAPA, 1997).

No período total, foi aplicado, em média, $50,8 \mathrm{~mm} \mathrm{semana}^{-1}$ de água residuária, em cada parcela experimental, o que representou uma dose de 78,27;6,53; e 10,29 $\mathrm{kg} \mathrm{ha}^{-1}$ semana $^{-1}$ de potássio, fósforo e cálcio, respectivamente (Tabela 1). Como os valores de N-total não foram determinados para a ARC aplicada, estimou-se, com base na concentração média de 196 $\mathrm{mg} \mathrm{L}^{-1}$, apresentada por Matos et al. (2001), a aplicação de 99,6 $\mathrm{kg} \mathrm{ha}^{-1}$ semana $^{-1}$ de N-total.

Foi aplicada também, durante o cultivo das forrageiras, água da rede de abastecimento (AA) da propriedade agrícola, no mesmo volume que a ARC e durante o mesmo período a fim de se constituir parcelas testemunha. Aos 28 dias após a semeadura, as parcelas destinadas a receber AA, e somente estas, foram adubadas com $40 \mathrm{~kg} \mathrm{ha}^{-1}$ de $\mathrm{K}_{2} \mathrm{O}$ e $40 \mathrm{~kg} \mathrm{ha}^{-1} \mathrm{de} \mathrm{N}$, nas formas de cloreto de potássio e uréia, respectivamente.

Antes e após o término do período de 17 semanas de aplicação da ARC e AA, em todas as parcelas experimentais foram coletadas amostras de solo, a fim de se investigar os possíveis efeitos da aplicação da ARC e AA nas suas características químicas. As amostras de solo foram coletadas nas profundidades de 0 a 0,$10 ; 0,10$ a 0,$20 ; 0,20$ a 0,$40 ; 0,40$ a 0,$60 ; 0,60$ a 0,$80 ;$ e 0,80 a $1,00 \mathrm{~m}$. Nas amostras coletadas de 0 a 0,10 e de 0,10 a $0,20 \mathrm{~m}$, foram determinados, no Laboratório de Rotina de Análises de Solo da UFV, o pH em água, com o uso de potenciômetro, as concentrações disponíveis de $\mathrm{P}$, por colorimetria, as concentrações trocáveis de $\mathrm{K}$, por fotometria de chama, as concentrações de $\mathrm{Ca}$ e $\mathrm{Mg}$ trocáveis por espectrofotometria de absorção atômica e as concentrações trocáveis de alumínio e a acidez potencial por titulometria (EMBRAPA, 1997). A soma de bases trocáveis e o índice de saturação por bases foram obtidos por cálculo, enquanto a CTC o foi pelo método da soma de bases trocáveis.
Tabela 1. Estimativa da quantidade de nutrientes aplicados semanalmente, em kg ha-1 ${ }^{-1}$ durante o período experimental

\begin{tabular}{rrrrrrr}
\hline${ }^{1 /}$ Semana Lâmina $(\mathrm{mm})$ & \multicolumn{1}{c}{$\mathrm{K}$} & \multicolumn{1}{c}{$\mathrm{P}$} & $\mathrm{Ca}$ & $\mathrm{N}^{2 / \mathrm{NO}_{3}}$ & $\mathrm{~N}^{-} \mathrm{NH}_{4}{ }^{+}$ \\
\hline 1 & 131,7 & 338,81 & 28,98 & ${ }^{3 /} \mathrm{NA}$ & 11,20 & 5,27 \\
2 & 114,4 & 294,13 & 25,16 & ${ }^{3 /} \mathrm{NA}$ & 9,72 & 4,57 \\
3 & 76,4 & 157,16 & 4,28 & ${ }^{3 /} \mathrm{NA}$ & 4,97 & 18,80 \\
5 & 34,1 & 71,85 & 6,12 & ${ }^{3 /} \mathrm{NA}$ & 1,34 & 9,26 \\
6 & 12,5 & 26,05 & 2,22 & ${ }^{3 /} \mathrm{NA}$ & 0,49 & 3,36 \\
7 & 32,6 & 76,85 & 5,87 & ${ }^{3 /} \mathrm{NA}$ & 1,08 & 6,04 \\
8 & 32,6 & 76,86 & 5,87 & ${ }^{3 /} \mathrm{NA}$ & 1,08 & 6,04 \\
9 & 35,1 & 25,49 & 5,86 & 12,27 & 1,82 & 1,37 \\
10 & 34,3 & 24,92 & 5,73 & 12,00 & 1,78 & 1,34 \\
11 & 34,1 & 34,89 & 3,58 & 14,96 & 2,66 & 12,98 \\
12 & 14,5 & 14,83 & 1,52 & 6,36 & 1,13 & 5,52 \\
13 & 37,8 & 21,05 & 3,85 & 11,98 & 1,85 & 2,49 \\
14 & 33,9 & 18,90 & 3,46 & 10,76 & 1,66 & 2,24 \\
15 & 57,4 & 32,56 & 0,92 & 4,59 & 4,77 & 3,33 \\
16 & 59,2 & 33,59 & 0,95 & 4,74 & 4,92 & 3,44 \\
17 & 71,8 & 4,45 & 0,17 & 14,93 & 4,74 & 1,30 \\
Total & 812,7 & $1.252,39$ & 104,55 & 164,60 & 55,19 & 87,33 \\
Média & 50,8 & 78,27 & 6,53 & 10,29 & 3,45 & 5,46 \\
\hline${ }^{1}$ Na quarta semana, a ARC não foi aplicada; ${ }^{2}$ Fósforo na forma de ortofosfato; ${ }^{3}$ Característica não \\
analisada na semana & & & & &
\end{tabular}

A quantificação da concentração de nitrato nas amostras de solo foi feita no Laboratório de Qualidade da Água do DEA/ UFV, utilizando-se o método baseado na reação de Gries-llosvay, com redução do nitrato a nitrito com solução de hidrazina, modificado por Mullin \& Riley (1955).

\section{RESULTADOS E DISCUSSÃO}

Observando-se as características químicas e físico-químicas do solo, na camada de 0 a $0,20 \mathrm{~m}$, antes do início do experimento (Tabela 2) e comparando-as com os valores apresentados pela Comissão de Fertilidade do Solo do Estado de Minas Gerais (CFSEMG, 1999), que apresenta as classes de interpretação da fertilidade do solo para o referido Estado, verificou-se que os

Tabela 2. Características químicas e físico-químicas do solo na camada de 0 a $0,20 \mathrm{~m}$ em cada bloco da área experimental, antes da implantação do experimento

\begin{tabular}{|c|c|c|c|c|c|}
\hline \multirow{2}{*}{ Características } & \multicolumn{5}{|c|}{ Blocos } \\
\hline & 1 & 2 & 3 & 4 & ${ }^{9 /}$ Média \\
\hline${ }^{1 /} \mathrm{pH}-\mathrm{H}_{2} \mathrm{O}$ & 5,8 & 6,4 & 6,6 & 6,7 & 6,4 \\
\hline${ }^{2 /} \mathrm{P}\left(\mathrm{mg} \mathrm{dm}^{-3}\right)$ & 6,5 & 41,1 & 118,0 & 149,1 & 78,7 \\
\hline${ }^{2 /} \mathrm{K}\left(\mathrm{cmol}_{\mathrm{c}} \mathrm{dm}^{-3}\right)$ & 0,3 & 0,3 & 0,4 & 0,5 & 0,4 \\
\hline${ }^{3 /} \mathrm{Ca}^{2+}\left(\mathrm{cmol}_{\mathrm{c}} \mathrm{dm}^{-3}\right)$ & 1,4 & 2,8 & 4,5 & 4,6 & 3,3 \\
\hline${ }^{3 /} \mathrm{Mg}^{2+}\left(\mathrm{cmol}_{\mathrm{c}} \mathrm{dm}^{-3}\right)$ & 0,4 & 0,6 & 0,9 & 0,9 & 0,7 \\
\hline${ }^{3 /} \mathrm{Al}^{3+}\left(\mathrm{cmol}_{\mathrm{c}} \mathrm{dm}^{-3}\right)$ & 0,0 & 0,0 & 0,0 & 0,0 & 0,0 \\
\hline${ }^{4 /}(\mathrm{H}+\mathrm{Al})\left(\mathrm{cmol}_{\mathrm{c}} \mathrm{dm}^{-3}\right)$ & 1,8 & 1,3 & 1,8 & 1,5 & 1,6 \\
\hline${ }^{5 /} \mathrm{SB}\left(\mathrm{cmol}_{\mathrm{c}} \mathrm{dm}^{-3}\right)$ & 2,1 & 3,7 & 5,8 & 6,0 & 4,4 \\
\hline${ }^{6 /} \mathrm{CTC}_{\mathrm{e}}\left(\mathrm{cmol}_{\mathrm{c}} \mathrm{dm}^{-3}\right)$ & 2,1 & 3,7 & 5,8 & 6,0 & 4,4 \\
\hline${ }^{\prime \prime} \mathrm{CTC}\left(\mathrm{cmol}_{\mathrm{c}} \mathrm{dm}^{-3}\right)$ & 3,9 & 5,0 & 7,6 & 7,5 & 6,0 \\
\hline${ }^{8 /} \mathrm{V}(\%)$ & 54 & 74 & 76 & 80 & 71 \\
\hline
\end{tabular}


solos utilizados para condução do experimento, à exceção do solo do bloco 1, estavam fora da condição de $\mathrm{pH}$, considerada ótima para o cultivo; entretanto, segundo Lopes (1989), ainda assim os solos usados no experimento se encontravam em condições consideradas produtivas.

Quanto à CTC efetiva e à CTC a pH 7,0 ou total, pelos valores médios encontrados, 4,4 $\mathrm{cmol}_{\mathrm{c}} \mathrm{dm}^{-3}$ e $6,0 \mathrm{cmol}_{\mathrm{c}} \mathrm{dm}^{-3}$, respectivamente, o solo pode ser classificado como de nível médio de fertilidade, ressaltando que o solo do bloco 1 apresentou baixa CTC a pH 7,0. Os valores médios de soma de bases e do índice de saturação por bases indicaram estarem os solos usados no experimento com bom nível de fertilidade.

Com a aplicação da ARC e da AA complementada pela adubação convencional, as características químicas do solo se alteraram. Sabe-se que o monitoramento das características químicas de um solo recebedor de águas residuárias é fundamental para que se possa atentar para os riscos de sua salinização ou de contaminação de águas subterrâneas; razão pela qual as alterações ocorridas serão discutidas de modo particular para alguns atributos químicos do solo, de importância do ponto de vista ambiental e cujos resultados foram significativamente alterados, de acordo com a análise de variância efetuada.

\section{Fósforo}

As altas concentrações de fósforo disponível encontradas nas amostras de solo coletadas na área experimental, antes do início dos tratamentos, se devem ao fato de ter sido o local utilizado, segundo informações obtidas, posteriormente, do proprietário, como área de descarte das cascas de frutos do cafeeiro, sabidamente ricas em nutrientes.

A concentração de fósforo no solo, após o período de condução do experimento foi exclusivamente influenciada $(\mathrm{P}<$ $0,05)$ pela qualidade da água aplicada nas parcelas experimentais (Tabela 3), tendo sido obtida maior concentração de fósforo no solo, ao final do período experimental, nas parcelas que receberam AA complementada por adubação convencional.

Tabela 3. Valores médios* da concentração de fósforo disponível no solo nas parcelas que receberam água de diferentes qualidades

\begin{tabular}{cc}
\hline Qualidade da Água & Concentração de Fósforo $\left(\mathrm{mg} \mathrm{dm}^{-3}\right)$ \\
\hline AA & $48,8 \mathrm{a}$ \\
ARC & $11,9 \mathrm{~b}$ \\
\hline * Médias seguidas pelas mesmas letras não diferem entre si, a $5 \%$ de probabilidade, pelo teste de Tuke
\end{tabular}

No que se refere à concentração de $\mathrm{P}$ disponível, segundo as classes de interpretação da fertilidade do solo para o Estado de Minas Gerais (CFSEMG, 1999), o solo das parcelas experimentais que receberam AA permaneceu classificado como de muito boa fertilidade, enquanto aqueles submetidos à aplicação da água residuária passaram a sê-lo como de baixa fertilidade.

Comparando-se os valores de concentração de fósforo disponível no solo antes e após o cultivo das espécies forrageiras, verifica-se que houve redução nessas concentrações no solo, o que pode estar associado à complexação do fósforo pela matéria orgânica adicionada ao solo com a ARC ou à formação de sais de baixa solubilidade (por exemplo, o fosfato de cálcio), ocorrendo, com isso, sua indisponibilização. A possibilidade dessa redução na disponibilidade do P no solo ser decorrente da absorção pelas plantas não pode ser comprovada pelos valores de produtividade das espécies forrageiras cultivadas nesses solos, já que as remoções médias de $\mathrm{P}$ foram relativamente baixas, sendo de $18,0 \mathrm{~kg} \mathrm{ha}^{-1}$ pela aveia, $29,4 \mathrm{~kg} \mathrm{ha}^{-1}$ pelo milheto e $37,0 \mathrm{~kg} \mathrm{ha}^{-1}$ pelo azevém, conforme dados apresentados por Pinto (2001).

\section{Potássio}

As elevadas concentrações de potássio nos solos, da mesma forma como foi explicado no caso do fósforo, se devem, em parte, ao aporte decorrente da mineralização das cascas de frutos do cafeeiro anteriormente depositadas na área. Desta forma, em média, os solos poderiam ser classificados como de muito boa fertilidade, no que se refere à concentração de $\mathrm{K}$ trocável, antes do início do experimento, já que eram superiores a $120 \mathrm{mg} \mathrm{dm}^{-3}$ (CFSEMG, 1999).

A concentração de potássio trocável no solo foi significativamente influenciada pela qualidade da água aplicada e pela profundidade do solo (Tabela 4); os resultados evidenciam que as parcelas tratadas com ARC mostraram concentrações $190 \%$ maiores que os das parcelas tratadas com AA e adubação convencional.

Solos das parcelas experimentais que receberam água da rede de abastecimento e adubação convencional (adubos potássicos e nitrogenados), após o cultivo das forrageiras, passaram a ser classificados como de média fertilidade. Atribuise, à grande absorção pelas plantas, a razão principal para o decréscimo na concentração desse nutriente no solo.

Com aplicação de ARC, a concentração média de K trocável no solo aumentou, passando de $0,40 \mathrm{mg} \mathrm{dm}^{-3}$ (Tabela 2) para $0,45 \mathrm{mg} \mathrm{dm}^{-3}$ (Tabela 4), mantendo-se a classificação de muito boa fertilidade para o solo, mesmo após o cultivo de forrageiras, que proporcionaram uma remoção média de $270,6 \mathrm{~kg} \mathrm{ha}^{-1}$, conforme dados apresentados por Pinto (2001); tal comportamento é, provavelmente, conseqüência das altas taxas de K (1.252,4 $\left.\mathrm{kg} \mathrm{ha}^{-1}\right)$ aplicadas por meio da ARC.

Em relação à profundidade, as maiores concentrações de potássio trocável foram encontradas na menor profundidade, ou seja, na camada de 0 a $0,10 \mathrm{~m}$ do solo. Embora o potássio seja considerado um cátion relativamente móvel no solo, o pequeno período de tempo de aplicação de ARC no solo, coincidente com o período de poucas chuvas, mostrou-se insuficiente para proporcionar maior lixiviação do cátion no solo. Embora isso possa ter contribuído para menor produtividade das plantas, em decorrência do efeito salino que o acúmulo desse nutriente pode ter provocado na camada superficial do solo, sob o ponto de vista ambiental, isso pode ser considerado um aspecto positivo para o controle da contaminação de águas subterrâneas.

\section{Cálcio}

A concentração de cálcio trocável no solo foi influenciada $(\mathrm{P}<0,05)$ pela qualidade da água aplicada e pela profundidade da camada de solo, sendo que as parcelas que receberam AA 
complementada com adubação convencional apresentaram concentrações de cálcio $\left(3,1 \mathrm{mg} \mathrm{dm}^{-3}\right)$ significativamente maiores que as parcelas que receberam ARC (Tabela 4).

Tabela 4. Valores médios da concentração de potássio e cálcio trocáveis no solo nas parcelas que receberam água de diferentes qualidades, em diferentes profundidades

\begin{tabular}{ccc}
\hline Qualidade da Água & $\mathrm{K}\left(\mathrm{cmol}_{\mathrm{c}} \mathrm{dm}^{-3}\right)$ & $\mathrm{Ca}\left(\mathrm{cmol}_{\mathrm{c}} \mathrm{dm}^{-3}\right)$ \\
\hline AA & $0,16 \mathrm{~b}$ & $3,1 \mathrm{a}$ \\
ARC & $0,45 \mathrm{a}$ & $2,4 \mathrm{~b}$ \\
$0-0,10$ & $0,36 \mathrm{a}$ & $3,1 \mathrm{a}$ \\
$0,10-0,20$ & $0,25 \mathrm{~b}$ & $2,4 \mathrm{~b}$ \\
\hline Dentro de cada variável, médias seguidas pelas mesmas letras, nas colunas, não diferem entre si,
\end{tabular}

a $5 \%$ de probabilidade, pelo teste de Tukey

A concentração média de cálcio trocável no solo diminuiu após a fase de cultivo das forrageiras e aplicação da AA e ARC, passando de 3,3 $\mathrm{cmol}_{\mathrm{c}} \mathrm{dm}^{-3}$ para 3,1 $\mathrm{cmol}_{\mathrm{cm}}^{-3} \mathrm{e} 2,4 \mathrm{cmol}$ $\mathrm{dm}^{-3}$, respectivamente. Os solos das parcelas submetidas à aplicação de AA permaneceram classificados como de boa fertilidade, enquanto os que receberam ARC passaram a ser classificados como de média fertilidade, em relação à concentração trocável deste nutriente, de acordo com a CFSEMG (1999). A menor disponibilidade de Ca trocável nas parcelas que receberam $\mathrm{ARC}$ pode estar associada à formação de precipitados de baixa solubilidade com o cálcio presente no solo.

Com relação à profundidade, a maior concentração de cálcio foi encontrada na camada de 0 a $0,10 \mathrm{~m}$ do solo, o que pode ser explicado pela baixa mobilidade desse cátion no solo e pela pequena ocorrência de chuvas no período de experimentação.

\section{Magnésio}

As concentrações médias de magnésio no solo, após o término do período experimental, foram influenciadas significativamente pela espécie forrageira cultivada e pela qualidade da água aplicada durante o período de cultivo.

A concentração de $\mathrm{Mg}$ diminuiu após o período de experimentação, passando de $0,7 \mathrm{cmol}_{c} \mathrm{dm}^{-3}$ (Tabela 2) para 0,6 $\mathrm{cmol}_{\mathrm{c}} \mathrm{dm}^{-3}$ e $0,4 \mathrm{cmol}_{c} \mathrm{dm}^{-3}$ (Tabela 5), nas parcelas que receberam $\mathrm{AA}$ e $\mathrm{ARC}$, respectivamente, de acordo com a CFSEMG (1999).

A menor concentração do $\mathrm{Mg}$ nas parcelas que receberam ARC pode significar carência do macronutriente na ARC ou, ainda, sua indisponibilização, em decorrência da formação de precipitados com os solutos adicionados com a ARC, forte

Tabela 5. Valores médios da concentração de magnésio trocável, no solo das parcelas cultivadas com diferentes gramíneas e qualidades de água aplicadas durante seu cultivo

\begin{tabular}{lc}
\hline Forrageira & $\mathrm{Mg}\left(\mathrm{cmol}_{\mathrm{c}} \mathrm{dm}^{-3}\right)$ \\
\hline Aveia-preta & $0,6 \mathrm{a}$ \\
Azevém & $0,5 \mathrm{ab}$ \\
Milheto & $0,4 \mathrm{~b}$ \\
Qualidade da água & \\
AA & $0,6 \mathrm{a}$ \\
ARC & $0,4 \mathrm{~b}$ \\
\hline $\begin{array}{l}\text { Dentro de cada variável, médias seguidas pelas mesmas letras não diferem entre si, a } 5 \% \text { de } \\
\text { probabilidade, pelo teste de Tukey }\end{array}$
\end{tabular}

indicativo de que a ARC, além de não ser boa fonte de Mg para o solo, pode ter diminuído sua disponibilidade à metade. Em vista disso, o Mg pode ter sido um dos nutrientes que, em baixa disponibilidade no solo, impediram melhor desenvolvimento das forrageiras fertirrigadas com ARC.

Em relação às gramíneas forrageiras, o solo das parcelas cultivadas com aveia-preta apresentou as maiores concentrações finais de magnésio trocável $\left(0,6 \mathrm{cmol}_{\mathrm{c}} \mathrm{dm}^{-3}\right)$, embora não tenha diferido significativamente do solo das parcelas cultivadas com o azevém. $\mathrm{O}$ fato da aveia preta só ter possibilitado a realização de um corte, é indicativo da menor capacidade dessa forrageira em absorver este e outros nutrientes do solo.

\section{Nitrato}

Na Figura 1 estão apresentadas as curvas de concentração de nitrato ao longo do perfil do solo, após o período de condução dos experimentos de aplicação de ARC e AA com adubação convencional, nas parcelas cultivadas com aveia preta, azevém e milheto.

A menor concentração de nitrato nas amostras do solo das camadas superficiais das parcelas submetidas à aplicação de AA e adubadas com uréia e cloreto de potássio, em relação àquelas que receberam $\mathrm{ARC}$, comprova que essa água residuária foi fonte de nitrato para as culturas. Como a ARC continha, em média, $196 \mathrm{mg} \mathrm{L}^{-1}$ de nitrogênio total esperar-se-ia que, após a sua aplicação no solo, ocorressem a mineralização do material orgânico e a conseqüente disponibilização de formas inorgânicas de nitrogênio, dentre as quais o nitrato.

Maiores concentrações de nitrato foram obtidas nas camadas superficiais do solo $(0$ a $0,10 \mathrm{~m})$ das parcelas experimentais que receberam a aplicação de ARC, independente da forrageira cultivada, o que pode ser atribuído ao aporte de $55,19 \mathrm{~kg} \mathrm{ha}^{-1}$ de $\mathrm{N}^{-\mathrm{NO}_{3}}$ - (Tabela 1) e de outras formas de nitrogênio que possam ter sido transformadas em nitrato após terem sido aplicadas ao solo.

As baixas concentrações de nitrato encontradas nas camadas mais profundas indicam que houve mobilidade relativamente baixa desse ânion no solo, o que pode ser devido, em parte, à ocorrência de poucas chuvas no período de experimentação (196,2 mm), que foi coincidente com o inverno.

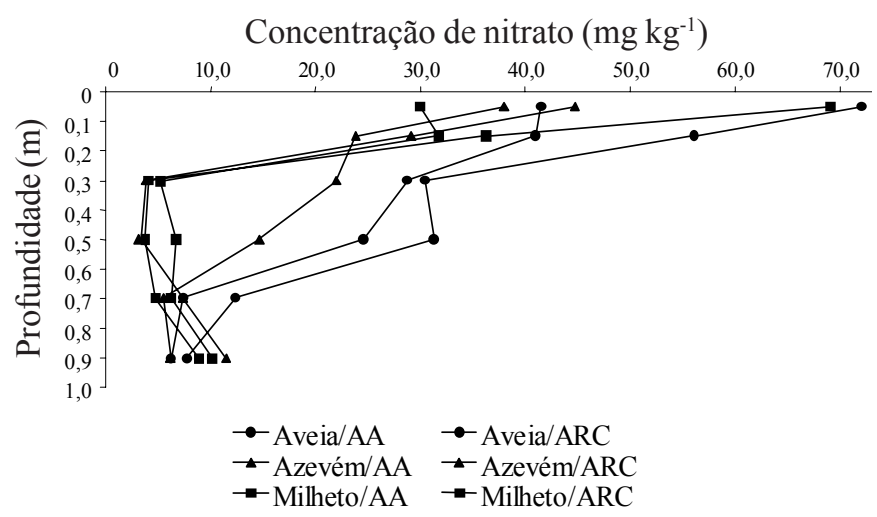

Figura 1. Concentração de nitrato, em $\mathrm{mg} \mathrm{kg}^{-1}$, em amostras de solo coletadas em diversas profundidades, nas parcelas experimentais cultivadas com diferentes gramíneas forrageiras, após serem submetidas à aplicação de $\mathrm{ARC}$ e de AA 
O balanço hídrico da água no solo indicou, para o período em que foi conduzido o experimento, maior saída de água por evapotranspiração que entrada com a precipitação.

Nos cultivos com aveia-preta, maiores concentrações de nitrato foram obtidas no solo das parcelas experimentais que receberam ARC, sendo que na camada de 0 a $0,10 \mathrm{~m}$ foi encontrada a maior concentração desse ânion no solo $(72,14$ $\left.\mathrm{mg} \mathrm{kg}^{-1}\right)$. Esses resultados podem estar associados principalmente à menor extração pela cultura, já que a aveia preta foi a forrageira de menor produtividade no período $(5,04$ t $\mathrm{ha}^{-1}$ ), conforme dados apresentados por Pinto (2001), em decorrência de não ter havido rebrota do vegetal após ser executado o primeiro corte, cessando, assim, a extração desse nutriente do solo.

Nas parcelas cultivadas com milheto que receberam AA ou ARC e naquelas cultivadas com azevém, encontraram-se as menores concentrações de nitrato nas camadas de $0,30-0,50 \mathrm{~m}$. Nos cultivos de azevém e milheto fertirrigados com ARC, as baixas concentrações de nitrato observadas na camada de 0,40 a $0,60 \mathrm{~m}$ indicam ter havido baixa mobilidade do nitrato no perfil. Por haver o azevém e o milheto fertirrigados com ARC apresentado relativamente altas concentrações de $\mathrm{N}$ no tecido vegetal, quantificadas na forma de proteína bruta $(18,79$ dag $\mathrm{kg}^{-1}$ e 12,66 dag kg ${ }^{-1}$, no primeiro corte, e 13,83 dag kg ${ }^{-1}$ e 16,41 dag $\mathrm{kg}^{-1}$ no segundo corte, respectivamente), segundo dados apresentados por Matos et al. (2003), o risco de lixiviação de nitrato no perfil do solo pode ser considerado baixo. Aos maiores desenvolvimento radicular e capacidade de absorção de nitrato pelas forrageiras, atribuem-se os valores encontrados.

Concordando com Alexander (1980), citado por Bayeer \& Mielniczuk (1993), a aveia-preta parece ter sido, dentre as espécies forrageiras avaliadas, a pior extratora de nitrato do solo, já que tanto nas parcelas que receberam ARC como nas que receberam AA, as maiores concentrações de nitrato em subsuperfície foram encontradas no solo das parcelas experimentais cultivadas com esta forrageira.

\section{CONCLUSÕES}

Com base nos resultados obtidos, conclui-se que:

1. Os nutrientes aplicados no solo por meio da ARC, à exceção do potássio, não foram suficientes para proporcionar acúmulo na camada de 0 a $0,20 \mathrm{~m}$ de profundidade.

2. A aplicação de ARC durante quatro meses de cultivo de azevém, aveia-preta e milheto proporcionou redução nas concentrações de $\mathrm{P}$ disponível, $\mathrm{Ca}$ e $\mathrm{Mg}$ trocáveis no solo.

3. Nas parcelas que receberam ARC, as maiores concentrações de nitrato foram observadas na camada superficial do solo de 0 a $0,10 \mathrm{~m}$, independentemente da forrageira cultivada.

4. O cultivo do milheto e do azevém, quando fertirrigado com ARC, proporcionou as menores concentrações de nitrato em subsuperfície (profundidade de 0,30-0,50 m) no solo

5. A aveia preta mostrou ser a pior extratora de nitrato do solo, dentre as espécies vegetais avaliadas.

\section{LITERATURA CITADA}

APHA - American Public Health Association - Standard methods for the examination of water and wastewater. New York: APHA, WWA, WPCR, 19. ed., 1995. s.n.p.

Bayer, C.; Mielniczuk, J. Manejo do solo: dinâmica do carbono, nitrogênio e rendimento do milho. In: Congresso Brasileiro de Ciência do Solo, 24, Goiânia, 1993. Cerrados. Fronteira agrícola do século 21. Resumos... Goiânia: SBCS, 1993.v.3, p.75-76.

Burns, J.C.; Westerman, P.W.; King, L.D.; Cummings, G.A.; Overcash, M.R.; Goode, L. Swine lagoon effluent applied to "Coastal" Bermudagrass: I Forage yield, quality and element removal. Journal of Environmental Quality, Madison, v.14, n.1,p.9-14, 1985.

Campos, J.M.C. Contaminación del agua em Costa Rica por residuos del procesamiento del café y de la porcinocultura. In: Prevención de la contaminación del agua por la agricultura y actividades afines. Santiago: FAO, 1993. p.113-124. Informe sobre temas hídricos, n.1

Carvalho, V.D.; Chagas, S.J.R.; Souza, S.M.C. Fatores que afetam a qualidade do café. Informe Agropecuário, Belo Horizonte, v.18, n.187, p.5-20, 1997.

CFSEMG - Comissão de Fertilidade do Solo do Estado de Minas Gerais. Recomendações para o uso de corretivos e fertilizantes em Minas Gerais ( $5^{\text {a }}$ aproximação). Viçosa: UFV, Imprensa Universitária, 1999.359p.

Coraucci Filho, B.; Chernicharo, C.A.L.; Andrade Neto, C.O.; Nour, E.A.; Andreoli, F.D. N.; Souza, H.N.; Monteggia, L.O.; Von Sperling, M.; Lucas Filho, M.; Aisse, M.M.; Figueiredo, R.F.; Stefanutti, R. Tecnologia do tratamento de águas residuárias no solo: infiltração rápida, irrigação e escoamento superficial. In: Tratamento de esgotos sanitários por processo anaeróbio e disposição controlada no solo. Rio de Janeiro: ABES, 1999. p.357-407.

EMBRAPA - Centro Nacional de Pesquisa de Solos. Manual de métodos de análise de solo. 2. ed. Rio de janeiro: EMBRAPA, 1997. 212 p. Documentos 1

Lopes, A.S. Manual de fertilidade do solo. São Paulo: ANDA/ POTAFOS, 1989. 155p.

Matos, A.T.; Lo Monaco, P.A.; Pinto, A.B.; Fia, R.; Fukunaga, D.C. Pollutant potential of wastewater of the coffee fruits processing. In: Inter-Regional Coference on EnvironmentWater, 4, 2001, Fortaleza. Proceedings... Brasília: ABID, 2001. p.158-165.

Matos, A.T.; Pinto, A.B.; Pereira, O.P.; Soares, A.A.; Lo Monaco, P.A. Produtividade de forrageiras utilizadas em rampas de tratamento de águas residuárias da lavagem e despolpa dos frutos do cafeeiro. Revista Brasileira de Engenharia Agrícola e Ambiental, Campina Grande, v.7, n.1, p.154-158, 2003.

Matos, A.T.; Sediyama, M.A.N.; Vidigal, S.M.; Garcia, N.C.P.; Ribeiro, M.F. Compostos orgânicos contendo dejeto líquido de suínos como fonte de nitrogênio: I - Dinâmica da compostagem. In: Congresso Brasileiro de Ciência do Solo, 24, Viçosa, 1995. Anais... Viçosa: UFV, Imprensa Universitária, 1995, p. 663-665. 
Matos, A.T.; Sediyama, M.A.N. Riscos potenciais ao ambiente pela aplicação de dejeto líquido de suínos ou compostos orgânicos no solo. In: Seminário Mineiro sobre Manejo e Utilização de Dejetos de Suínos, 1, Ponte Nova, 1995. Anais... Viçosa: EPAMIG, 1996. p.45-54.

Muchovej, R.M.C.; Rechcigl, J.E. Impacts of nitrogen fertilization of pastures and turfgrasses on water quality. In: Lal, R.; Stewart, B.A. (ed). Soil processes and water quality. Lewis Publication, Boca Raton, 1994, p.91-135.

Mullin, J.B.; Riley, J.P. The spectrophotometric determination of nitrate in naturals waters with particular reference to seawater. Analytic Chimica Acta, San Diego, v.12, p.464-480, 1955.

Oliveira, P.A.V. Manual de manejo e utilização dos dejetos de suínos. Concórdia: EMBRAPA/CNPSA, 1993. 188p. Documentos, 27
Owens, L.B. Impacts of soil N management on the quality of surface and subsurface water. In: Lal, R.; Stewart, B.A. ed. Soil processes and water quality. Boca Raton: Lewis Publication, 1994, p.137-162.

Pinto, A.B. Avaliação de gramíneas forrageiras com uso de águas residuárias da lavagem de frutos do cafeeiro em rampas de tratamento. Viçosa: UFV, 2001. 108p. Dissertação Mestrado

Silva, J.S.; Berbert, P.A. Colheita, secagem e armazenamento de café. 1.ed. Viçosa: Aprenda Fácil, 1999. 146p.

Westerman, P.W.; King, L.D.; Burns, J.C.; Cummings, G.A.; Overcash, M.R. Swine manure and lagoon effluent applied to a temperate forage mixture II Rainfall runoff and soil chemical properties. Journal of Environmental Quality, Madison, v.16, n.2, p.106-112, 1987. 